\title{
Development of HPLC Method for Determination of Phenolic Compounds on a Core Shell Column by Direct Injection of Wine Samples
}

\author{
Milica Atanacković Krstonošić ${ }^{*}$, Jelena Cvejić Hogervorst ${ }^{1}$, \\ Mira Mikulić $^{1}$ and Ljiljana Gojković-Bukarica ${ }^{2}$ \\ 'Department of Pharmacy, Faculty of Medicine, University of Novi Sad, Hajduk Veljkova 3, 21000 Novi Sad, Serbia \\ Department of Pharmacology and Toxicology and Clinical Pharmacology, Faculty of Medicine, University of Belgrade, \\ P.O. Box 840, 11129 Belgrade, Serbia
}

Received: 20 February 2019; accepted: 28 February 2019

\begin{abstract}
Phenolic compounds are frequently present in various natural products, and they can have different beneficial biological potentials. The most widely used method for determination of individual phenolic compounds is high-performance liquid chromatography (HPLC). In this paper, a method for simultaneous determination of 16 phenolic compounds (gallic acid, $p$-hydroxybenzoic acid, catechin, syringic acid, trans-cinnamic acid, hesperetin, naringenin, vanillic acid, benzoic acid, coumaric acid, resveratrol, chlorogenic acid, caffeic acid, rutin, quercetin, and kaempferol) on a core-shell column was developed. The separation method conducted on a standard ODS (250 mm) column was transferred to Poroshell column and optimized using non-ultra-high-performance liquid chromatography (UHPLC) apparatus. Phenolic compounds were separated fast and efficiently during 30-min analysis, and validation parameters were determined. The developed method was successfully applied on the analysis of phenolic content after direct injection of red wines from three different grape varieties.
\end{abstract}

Keywords: HPLC, core shell column, phenolics, wine

\section{Introduction}

Phenolic compounds are widely present among natural products, and they can express different beneficial biological activities. Some of them include antioxidant, cardioprotective, anticancer, anti-inflammation, and anti-aging properties [1]. Red wine is well-known for its health benefits, and most of them are, at least partially, attributed to the presence of phenolic compounds [2]. During winemaking procedure, phenolics are transferred from grapes to wine, but the final phenolic content in wine depends on many factors including grape variety [3], grape maturity [4], and the winemaking technology applied [5, 6].

The most widely used method for determination of individual phenolic compounds in red wine is high-performance liquid chromatography (HPLC). It can be coupled with ultraviolet/diode array detection (UV/DAD) [3, 7], fluorescence $[8,9]$, and MS detection [10]. Some recently published methods include also gas chromatography coupled with mass spectrometry (GC-MS) [11] and capillary electrophoresis [12].

Fang et al. [7] reported detection of 12 phenolics with UV/ DAD after direct injection of wines samples during 60-min analysis time. In the study published by Bravo et al. [10], 25 phenolic compounds were determined with MS detection after extraction of red wine with ethyl acetate. Analysis duration time was $110 \mathrm{~min}$. Fluorescence and UV-vis photodiode array (DAD) detection was applied for the analysis of 23 phenols after direct injection and 90-min long chromatographic analysis [8]. Burin et al. developed 60-min long method with UV/ DAD detection for determination of 5 phenolic compounds in wine without sample preparation [13].

In general, the most accessible detector that could be used for phenolic analysis in these types of samples is DAD. Due

*Author for correspondence: milica.atanackovic-krstonosic@mf.uns.ac.rs. to the various profile of phenolic compounds present in wine, it is useful to have methods that provide simultaneous determination of a large number of phenolic compounds in a single run. Usually, for these types of analysis, C18 250-mm-long columns are used, consequently having long duration time (up to $100 \mathrm{~min})[10,13]$. These methods are usually not costeffective due to the large solvent consumption and long analysis time.

In some recently published studies, in order to decrease analysis duration time, core-shell particle columns have been suggested as a substitute for commonly used long columns [14]. A solid core and a porous or a superficially porous shell can provide efficient separation with relatively fast rate and low back pressure $[15,16]$. Combination of core and shell gives a larger particle and enables low operating back pressure while enabling higher surface area for the separation to occur [16]. Core-shell columns were employed for the analysis of over 20 phenolic compounds in wine [17] and grape-related products [18]. Still, for the efficient application of these methods, the optimized HPLC or ultra-HPLC (UHPLC) apparatus is often recommended, but this equipment is not available in every laboratory [14]. As far as the authors are aware, there are only a few published rapid methods for wine phenolic analysis using conventional HPLC and the core-shell column $[19,20]$.

Therefore, the aim of this paper is to develop a simple method for the simultaneous determination of 16 selected phenolic compounds in wine using core-shell column on a conventional HPLC apparatus with UV/DAD detection. The developed method will provide a time-effective analysis of phenolics in samples without preparation (directly injected) using apparatus accessible in laboratories which have basic analytical equipment.

This is an open-access article distributed under the terms of the Creative Commons Attribution-NonCommercial 4.0 International License (https://creativecommons.org/licenses/by-nc/4.0/), which permits unrestricted use, distribution, and reproduction in any medium for non-commercial purposes, provided the original author and source are credited, a link to the CC License is provided, and changes - if any - are indicated. 


\section{Experimental}

2.1. Standards and Reagents. Phenolic standards, namely, rutin, naringenin, chlorogenic acid, trans-cinnamic acid, quercetin, $p$-coumaric acid, caffeic acid, $p$-hydroxybenzoic acid, syringic acid, vanillic acid, resveratrol, and kaempferol were purchased from Sigma (Steinheim, Germany), while hesperetin and catechin were purchased from Fluka (Steinheim, Germany). Benzoic acid was obtained from Lacinema (Neratovice, Czech Republic), and gallic acid from Alfa Aesar (Lancaster, Great Britain). The purities of standards were up to $99 \%$. The solvents used were of analytical grade, dimethyl sulfoxide (DMSO) (J.T. Baker, NJ, USA), glacial acetic acid (POCH, Gliwice, Poland), and HPLC-grade acetonitrile (J.T. Baker, NJ, USA). Quantification was performed by the external standard method. The standard stock solutions (1-25 mg/L) were made using dimethyl sulfoxide as solvent.

2.2. HPLC Analysis. Phenolic compounds were determined by an HPLC method using an Agilent 1100 Series liquid chromatograph (USA) equipped with a UV/DAD detector. Chromatographic separation was performed on a Poroshell 120 EC-C18 $(4.6 \mathrm{~mm} \times 100 \mathrm{~mm}, 2.7 \mu \mathrm{m})$ column. The solvent system had a constant flow rate of $1.0 \mathrm{~mL} / \mathrm{min}$. The mobile phase was distilled water with $0.1 \%$ glacial acetic acid (solvent $\mathrm{A}$ ) and acetonitrile with $0.1 \%$ glacial acetic acid (solvent B). The gradient was as follows: $0-3.25 \mathrm{~min}, 8-10$ $\% \mathrm{~B} ; 3.25-8 \mathrm{~min}, 10-12 \% \mathrm{~B} ; 8-15,12-25 \% \mathrm{~B} ; 15-15.8 \mathrm{~min}$, $25-30 \% \mathrm{~B} ; 15.8-25 \mathrm{~min}, 30-90 \% \mathrm{~B}$; 25-25.4 min, 90-100 $\% \mathrm{~B}$; and $25.4-30 \mathrm{~min}, 100 \% \mathrm{~B}$. The injection volume was $5 \mu \mathrm{L}$, and the temperature was kept constant at $25^{\circ} \mathrm{C}$. Detection wavelengths were chosen considering the absorption maximums of UV spectra of the selected phenolic compounds. Gallic acid,

Table 1. (a) Elution program obtained from Agilent's Infinity Method Transfer and (b) final elution program

\begin{tabular}{lccc}
\hline a) & & b) & \\
\cline { 3 - 4 } Min & $\mathrm{B}(\%)$ & & Min \\
\hline 0 & 8 & 0 & 8 \\
0.8 & 10 & 3.25 & 10 \\
10 & 25 & 8 & 12 \\
10.8 & 30 & 15 & 25 \\
20 & 90 & 15.80 & 30 \\
20.4 & 100 & 25 & 90 \\
24 & 8 & 25.40 & 100 \\
30 & 8 & 27 & 8 \\
\hline
\end{tabular}

p-hydroxybenzoic acid, catechin, syringic acid, trans-cinnamic acid, hesperetin, and naringenin were detected on $280 \mathrm{~nm}$, vanillic and benzoic acid on $225 \mathrm{~nm}$, coumaric acid and resveratrol on $305 \mathrm{~nm}$, and chlorogenic and caffeic acid on $330 \mathrm{~nm}$, while rutin, quercetin, and kaempferol were monitored on $360 \mathrm{~nm}$.

2.3. Samples. In order to apply the developed method, 3 samples of commercially available red wines from Serbia were analyzed (Prokupac, Pinot Noir, and Cabernet Sauvignon). Sample Pinot Noir was diluted five times with distilled water for catechin analysis. Samples were filtered through Agilent Technologies Econofilter 0.45- $\mu \mathrm{m}$ RC prior to HPLC injection.

2.4. Statistical Analysis. The data were analyzed statistically using Excel for Windows 2007. The Origin 8.1. program was used for the analysis of variance (ANOVA) of the obtained results. The differences were considered significant at level 0.05 .

\section{Results and Discussion}

3.1. Optimization of Mobile Phase. An HPLC method was developed in order to perform the analysis of 16 selected phenolic compounds in red wine in a time-efficient manner. A separation method performed on a standard ODS $(250 \mathrm{~mm})$ column was transferred to Poroshell column and optimized. In order to define the elution program, a previously published HPLC method for determination of phenolic compounds by Kim et al. [21] was used. The proposed method was transferred from standard ODS $(250 \mathrm{~mm})$ to Poroshell column using an Agilent transfer method calculator [22]. Gradient program obtained in that way is presented in Table 1 (a). The analysis of the selected phenolic standard mixture showed that this procedure was not suitable for the adequate separation, and therefore further modifications of elution program were necessary.

Injection of individual standard solutions showed that coelution of caffeic and syringic acids occurs at $5.88 \mathrm{~min}$. Therefore, the initial gradient was prolonged. As this modification led to co-elution of chlorogenic and hydroxybenzoic acids, additional changes in the elution program were made until the final gradient presented in Table 1 (b) was established. The total run time for the analysis of 16 phenolics was $30 \mathrm{~min}$. This is more efficient concerning time and solvent consumption than some previously mentioned methods $[8,13]$. The resulting chromatogram of the mixture of standard substances is presented in Figure 1.

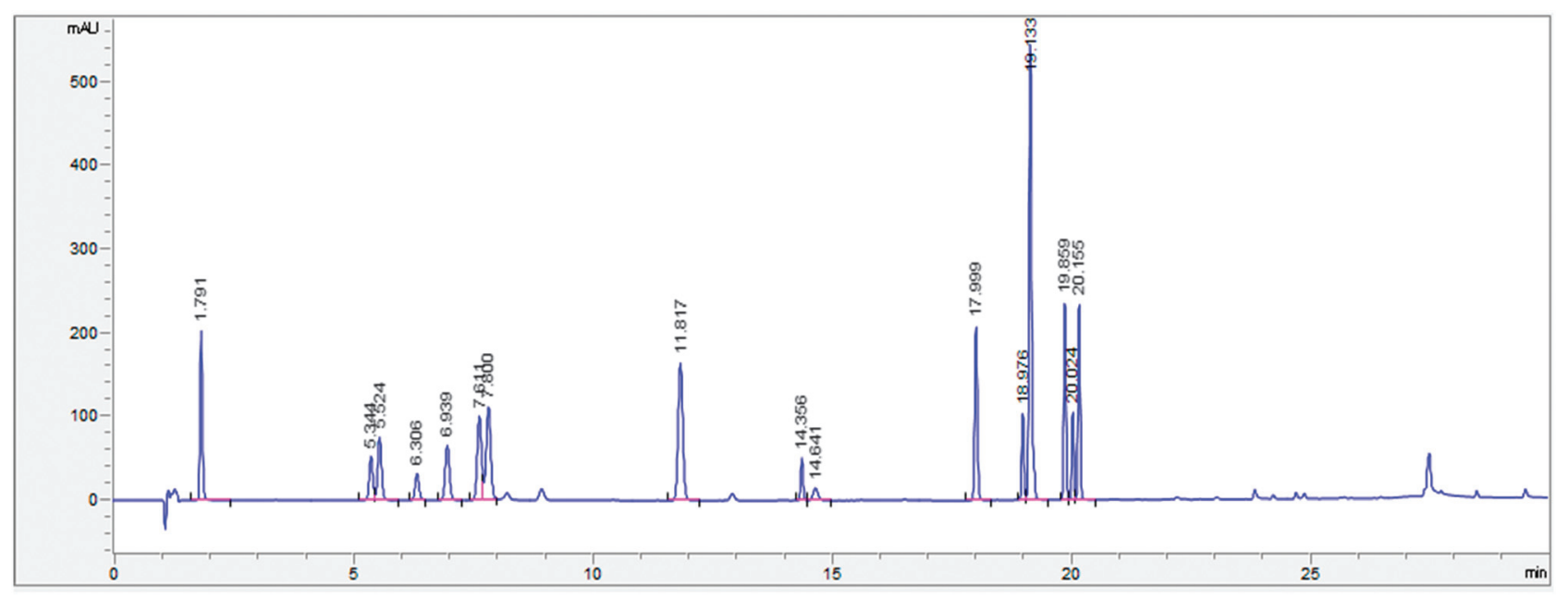

Figure 1. Final chromatogram of the standard mixture $(\lambda=280 \mathrm{~nm})(1.791$ - gallic acid, 5.344 - chlorogenic acid, 5.524 - $p$-hydroxybenzoic acid, 6.306 - catechin, 6.939 - vanillic acid, 7.611 - caffeic acid, 7.800 - syringic acid, 11.817 - p-coumaric acid, 14.365 - rutin, 14.641 - benzoic acid, 17.999 - trans-resveratrol, 18.976 - quercetin, 19.133 - trans-cinnamic acid, 18.976 - naringenin, 20.024 - kaempferol, and 20.135 - hesperetin) 
3.2. Validation Parameters. After the HPLC conditions were established, validation parameters were determined according to the International Council for Harmonization (ICH) guidelines [23]. Calibration curves were constructed using 6 concentration levels $(1,2.5,5,10,15$, and $25 \mathrm{mg} / \mathrm{L})$ for all analyzed compounds except vanillic acid and catechin. For vanillic acid and catechin, the concentrations used for calibration curve construction were $2.5,5,10,15$, and $25 \mathrm{mg} / \mathrm{L}$. Concentration ranges were established according to the expected concentration of phenolic compounds in wine samples. Standard solutions were injected five times, and each component was detected on corresponding wavelength. Table 2 presents summarized results including retention time of each substance, calibration curve equation, and determination coefficients. High values of determination coefficient suggest a good fitting of the curves.

Reproducibility of HPLC analysis was examined by injection of standard mixture $10 \mathrm{mg} / \mathrm{L}$ concentration level ten times and calculation of coefficient of variation $(\mathrm{CV})$ of retention times. The results are listed in Table 2, and it can be seen that $\mathrm{CV}$ of retention times are below $1 \%$, which is acceptable as previously mentioned by Fang et al. [7].

Values of limit of detection (signal-to-noise ratio of 3:1) and limit of quantification LOQ (signal-to-noise ratio of 10:1) for each compound are listed in Table 3. A slightly higher LOD values are noticed for vanillic acid and catechin in comparison with other analyzed compounds, which is due to the lower sensitivity of UV detection for both of these compounds. However, these levels are still appropriate for their analysis in red wine. Quantification limits were below $1 \mathrm{mg} / \mathrm{L}$ for all compounds except for catechin and vanillic acid, for which the values were $2.08 \mathrm{mg} / \mathrm{L}$ and $1.46 \mathrm{mg} / \mathrm{L}$, respectively.

In order to determine how well 2 elution peaks can be differentiated, the resolution between critical pairs was determined. Results are presented in Table 4 and show that all adjacent peaks have resolution higher than 1.5 , which indicates that the separation is satisfactory as previously discussed by Snyder et al. [24].

The accuracy of the method was tested by analysis of standard mixture that contained $10 \mathrm{mg} / \mathrm{L}$ of each standard substance and quantification with constructed calibration curves (Table 5). The mean recovery was calculated by comparison between the calculated amounts and the amount present in the standard solution. High mean recovery values (above 95\%) for all analyzed compounds indicate high accuracy of the method. A similar observation was established for polyphenol determination in red wine by Cvetković et al. [25].

3.3. Method Application on Wine Analysis. The developed method was applied for the analysis of phenolic
Table 3. Limits of detection and quantification for 16 analyzed phenolic compounds

\begin{tabular}{lcc}
\hline Compound & $\begin{array}{c}\text { Limit of detection } \\
(\mathrm{mg} / \mathrm{L})\end{array}$ & $\begin{array}{c}\text { Limit of quantification } \\
(\mathrm{mg} / \mathrm{L})\end{array}$ \\
\hline Gallic acid & 0.09 & 0.31 \\
Chlorogenic acid & 0.08 & 0.29 \\
$p$-Hydroxybenzoic acid & 0.26 & 0.89 \\
Catechin & 0.62 & 2.08 \\
Vanillic acid & 0.43 & 1.46 \\
Caffeic acid & 0.04 & 0.14 \\
Syringic acid & 0.16 & 0.54 \\
$p$-Coumaric acid & 0.05 & 0.18 \\
Rutin & 0.10 & 0.36 \\
Benzoic acid & 0.18 & 0.62 \\
Trans-resveratrol & 0.03 & 0.11 \\
Quercetin & 0.04 & 0.16 \\
Trans-cinnamic acid & 0.03 & 0.11 \\
Naringenin & 0.04 & 0.13 \\
Kaempferol & 0.07 & 0.25 \\
Hesperetin & 0.06 & 0.20 \\
\hline
\end{tabular}

compounds in 3 red-wine commercial samples produced from different grape varieties (Prokupac, Pinot Noir, and Cabernet Sauvignon). Wine samples were filtered, directly injected, and analyzed under established chromatographic conditions. A representative chromatogram of wine sample (Prokupac) on $280 \mathrm{~nm}$ is presented in Figure 2.

Analyses were performed in triplicate. Identification and quantification of the present phenolic compounds was performed by observing chromatograms on characteristic wavelengths. Identification was achieved by comparison of retention times, as well as the UV spectra of the phenolic compounds. The obtained results are presented in Table 6 .

As it can be seen in Table 6, phenolic compound content differs in wine samples. In total, the highest concentration of phenolic compounds was observed in Pinot Noir wine (141.75 mg/L), while the lowest was in Prokupac wine $(51.21 \mathrm{mg} / \mathrm{L})$. Gallic acid, catechin, syringic acid, $p$-coumaric acid, and trans-cinnamic acid were detected in all analyzed wines. Resveratrol, benzoic acid, rutin and $p$-hydroxybenzoic acid were detected in two samples (Pinot Noir and Cabernet

Table 4. Resolution between critical pairs

\begin{tabular}{lc}
\hline Compounds & Resolution \\
\hline Chlorogenic/4-hydroxybenzoic acid & 1.64 \\
Caffeic/Syringic acid & 1.85 \\
Rutin/Benzoic acid & 3.87 \\
Quercetin/trans-cinnamic acid & 2.94 \\
Naringenin/ Kaempferol & 3.34 \\
Kaempferol/Hesperetin & 2.64 \\
\hline
\end{tabular}

Table 2. Calibration curve data for 16 analyzed phenolic compounds

\begin{tabular}{|c|c|c|c|c|}
\hline Compound & Retention time (min) & Retention time CV (\%) & Calibration curve & Coefficient of determination $\left(R^{2}\right)$ \\
\hline Gallic acid & 1.791 & 0.42 & $y=15 x-1.2482$ & 0.9998 \\
\hline Chlorogenic acid & 5.344 & 0.87 & $y=13.293 x-2.9894$ & 0.9999 \\
\hline$p$-Hydroxybenzoic acid & 5.524 & 0.49 & $y=8.7932 x+0.0663$ & 1 \\
\hline Vanillic acid & 6.938 & 0.49 & $y=23.076 x+0.3703$ & 0.9999 \\
\hline Caffeic acid & 7.611 & 0.53 & $y=25.908 x-3.8534$ & 0.9998 \\
\hline Syringic acid & 7.800 & 0.83 & $y=15.295 x+0.0054$ & 0.9995 \\
\hline$p$-Coumaric acid & 11.817 & 0.26 & $y=40.025 x-1.723$ & 0.9996 \\
\hline Benzoic acid & 14.541 & 0.17 & $y=22.697 x-1.9559$ & 0.9998 \\
\hline Trans-resveratrol & 17.999 & 0.06 & $y=38.253 x-8.269$ & 0.9993 \\
\hline Quercetin & 18.976 & 0.04 & $y=18.092 x-2.4305$ & 0.9999 \\
\hline Trans-cinnamic acid & 19.133 & 0.03 & $y=42.684 x+5.8327$ & 0.9999 \\
\hline Naringenin & 19.859 & 0.02 & $y=15.76 x+3.6043$ & 0.9993 \\
\hline Kaempferol & 20.024 & 0.02 & $y=19.005 x-0.245$ & 0.9998 \\
\hline Hesperetin & 20.155 & 0.56 & $y=15.249 x+3.0552$ & 0.9992 \\
\hline
\end{tabular}


Table 5. Recovery and accuracy of the proposed method

\begin{tabular}{lccc}
\hline $\begin{array}{l}\text { Compound } \\
(\mathrm{mg} / \mathrm{L})\end{array}$ & $\begin{array}{c}\text { Calculated concentration } \\
(\mathrm{mean} \pm \mathrm{SD})\end{array}$ & $\begin{array}{c}\text { Mean recovery } \\
(\%)\end{array}$ & $\begin{array}{c}\text { Accuracy } \\
(\%)\end{array}$ \\
\hline Gallic acid & $9.79 \pm 0.03$ & 97.9 & -2.1 \\
Chlorogenic acid & $9.85 \pm 0.02$ & 98.5 & -1.5 \\
$p$-Hydroxybenzoic acid & $9.97 \pm 0.06$ & 99.7 & -0.3 \\
Catechin & $10.09 \pm 0.05$ & 100.9 & +0.9 \\
Vanillic acid & $10.04 \pm 0.04$ & 100.4 & +0.4 \\
Caffeic acid & $9.86 \pm 0.01$ & 98.6 & -1.4 \\
Syringic acid & $9.96 \pm 0.05$ & 99.6 & -0.4 \\
$p$-Coumaric acid & $9.90 \pm 0.01$ & 99.0 & -1.0 \\
Rutin & $9.65 \pm 0.01$ & 96.5 & -3.5 \\
Benzoic acid & $9.80 \pm 0.03$ & 98.0 & -2.0 \\
Trans-resveratrol & $10.03 \pm 0.01$ & 100.3 & +0.3 \\
Quercetin & $9.90 \pm 0.01$ & 99.0 & -1.0 \\
Trans-cinnamic acid & $10.15 \pm 0.03$ & 101.5 & +1.5 \\
Naringenin & $9.95 \pm 0.02$ & 99.5 & -0.5 \\
Kaempferol & $10.13 \pm 0.02$ & 101.3 & +1.3 \\
Hesperetin & $10.24 \pm 0.03$ & 102.4 & +2.4 \\
\hline
\end{tabular}

Sauvignon), while naringenin and quercetin were present only in Cabernet Sauvignon wine. Caffeic and vanillic acid were abundant only in one of the analyzed wine sample (Pinot Noir and Prokupac, respectively). Furthermore, significant differences were noticed $(p<0.05)$ between the contents of phenolic compounds in wine from different grape varieties. The most abundant phenols in all three wine samples were gallic acid and catechin.

All analyzed samples had relatively high concentrations of gallic acid (above $20 \mathrm{mg} / \mathrm{L}$ ). This is in accordance with the results for gallic acid content in Spanish red wines, but these values can go up to $50 \mathrm{mg} / \mathrm{L}$ [26]. Another study performed on red wines from Croatia showed that gallic acid was a dominant phenol with values up to $37 \mathrm{mg} / \mathrm{L}$ [27].

Catechin was detected in the range from 20.13 to $108.50 \mathrm{mg} / \mathrm{L}$. This is expected, since it has been shown that catechin is one of the most abundant phenols present in red wine [28]. For example, red wines from native Greek grape cultivars contained up to $113 \mathrm{mg} / \mathrm{L}$ of catechin [29], and Cabernet Sauvignon red wine from Brazil contained $50 \mathrm{mg} / \mathrm{L}$, which is almost two times higher than the value observed for the same variety in this experiment [13]. Wine made from Pinot Noir grape variety had by far the highest concentration of catechin when compared with the other two analyzed samples. This is in accordance with the results published by Soleas et al. [30], where Pinot Noir wine had the highest catechin concentration among 5 red grape varieties (Pinot Noir,
Table 6. Mean concentrations $(\mathrm{mg} / \mathrm{L})$ of phenolic compounds in analyzed wine samples $(n=3)$

\begin{tabular}{lccc}
\hline Sample $^{a}($ mean $\pm \mathrm{SD})$ & & & \\
\hline $\mathrm{mg} / \mathrm{L}$ & Prokupac & Pinot Noir & Cabernet Sauvignon \\
\hline Gallic acid & $20.25 \pm 0.02^{\mathrm{a}}$ & $22.88 \pm 0.03^{\mathrm{b}}$ & $20.06 \pm 0.02^{\mathrm{c}}$ \\
$p$-Hydroxybenzoic acid & $2.13 \pm 0.04^{\mathrm{a}}$ & $0.77 \pm 0.03^{\mathrm{b}}$ & - \\
Catechin & $20.13 \pm 0.08^{\mathrm{a}}$ & $108.50 \pm 0.02^{\mathrm{b}}$ & $32.95 \pm 0.14^{\mathrm{c}}$ \\
Vanillic acid & $1.05 \pm 0.05$ & - & - \\
Caffeic acid & - & $0.38 \pm 0.02$ & - \\
Syringic acid & $3.14 \pm 0.09^{\mathrm{a}}$ & $5.92 \pm 0.05^{\mathrm{b}}$ & $5.26 \pm 0.16^{\mathrm{c}}$ \\
$p_{\text {-Coumaric acid }}$ & $1.56 \pm 0.09^{\mathrm{a}}$ & $1.18 \pm 0.01^{\mathrm{b}}$ & $1.41 \pm 0.07^{\mathrm{c}}$ \\
Rutin & $2.64 \pm 0.03^{\mathrm{a}}$ & - & $1.27 \pm 0.04^{\mathrm{b}}$ \\
Benzoic acid & - & $1.69 \pm 0.09^{\mathrm{a}}$ & $0.95 \pm 0.04^{\mathrm{b}}$ \\
Trans-resveratrol & - & $0.31 \pm 0.01^{\mathrm{a}}$ & $0.29 \pm 0.01^{\mathrm{b}}$ \\
Quercetin & - & - & $0.55 \pm 0.04$ \\
Trans-cinnamic acid & $0.31 \pm 0.01^{\mathrm{a}}$ & $0.12 \pm 0.005^{\mathrm{b}}$ & $0.13 \pm 0.005^{\mathrm{b}}$ \\
Naringenin & - & - & $0.16 \pm 0.01$ \\
Total & 51.21 & 141.75 & 63.03 \\
$\quad{ }^{a}$ Different letters in the same row indicate significant difference \\
$\quad(p<0.05)$ between the samples; -- not detected. \\
\hline
\end{tabular}

Cabernet Sauvignon, Cabernet Franc, Merlot, and Gamay Noir). Also, a global survey of catechin concentration in over 800 red wines from different regions has shown that Pinot Noir wines have the highest catechin content regardless of the wine origin [31].

Trans-resveratrol, one of the most recognized phenols for its health benefits, was detected only in two samples (Pinot Noir and Cabernet Sauvignon). Earlier reported values for resveratrol content in red wines from Serbia are $0.50 \mathrm{mg} / \mathrm{L}$ (Prokupac), $1.74 \mathrm{mg} / \mathrm{L}$ (Pinot Noir), and 0.18-2.37 mg/L (Cabernet Sauvignon) [6, 32]. Also, in another study performed on samples from the Balkan region (Romanian wines), it was established that Cabernet Sauvignon had $8.8 \mathrm{mg} / \mathrm{L}$ of trans-resveratrol and Pinot Noir had $1.68 \mathrm{mg} / \mathrm{L}$, which are higher concentrations than those obtained for the samples analyzed [33].

Concerning other abundant phenols, syringic acid was detected in a relatively high concentration (3.14-5.92 mg/L). Some of the previously published values for this compound include $2.2-3.9 \mathrm{mg} / \mathrm{L}$ for Italian commercial red wines [34], but these values can reach up to $76 \mathrm{mg} / \mathrm{L}$ as reported for Macedonian Vranec wines by Ivanova-Petropulos et al. [35]. The observed differences in the phenolic content could be attributed to many factors, including varietal characteristics, and geographical origin, as well as the applied winemaking technology [5].

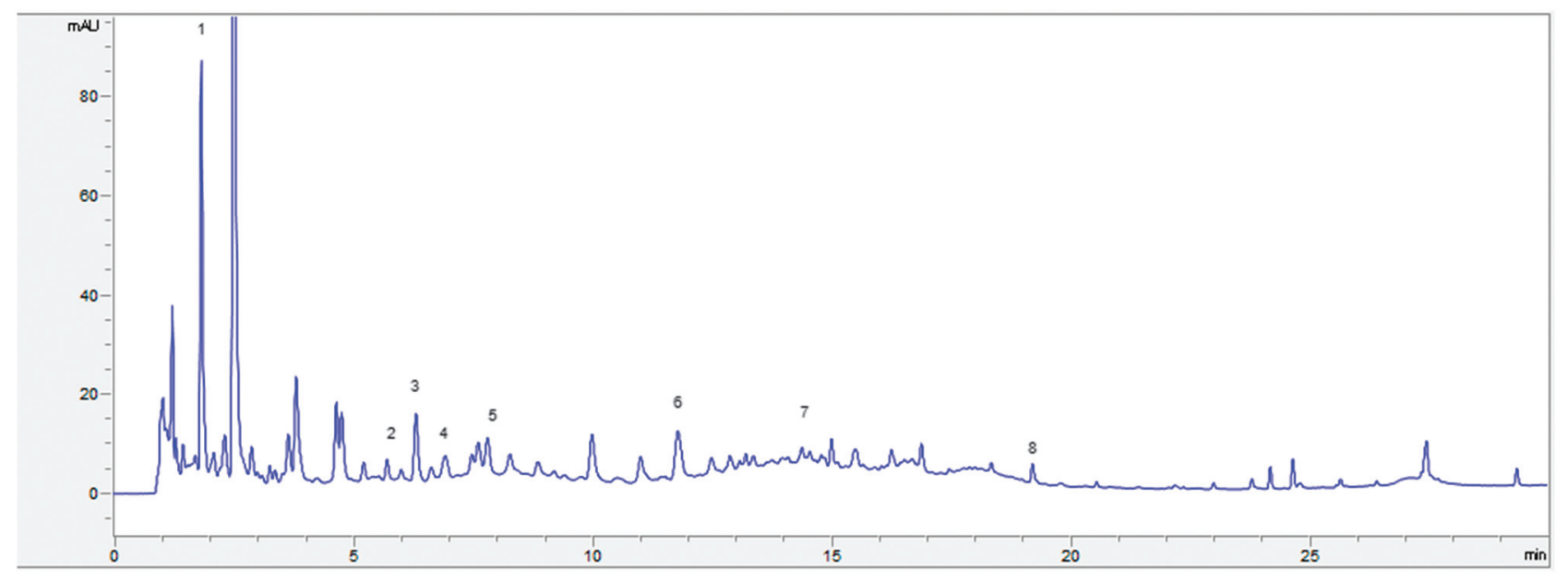

Figure 2. Chromatogram of the Prokupac wine sample $(\lambda=280 \mathrm{~nm})(1-$ gallic acid, 2 - $p$-hydroxybenzoic acid, 3 - catechin, 4 - vanillic acid, 5 - syringic acid, 6 - $p$-coumaric acid, 7 - rutin, and 8 - trans-cinnamic acid) 


\section{Conclusion}

In this paper, a time-effective HPLC method for simultaneous determination of 16 phenolic compounds in wine using core-shell column is proposed. The method was optimized after the transfer from standard ODS $250 \mathrm{~mm}$ to the Poroshell $(4.6 \times 100 \mathrm{~mm}, 2.7 \mu \mathrm{m})$ column. The final program includes gradient elution, direct injection of the sample, and UV/DAD detection during 30-min run time. A satisfactory separation is accomplished for standards, as well as for the samples with the use of conventional apparatus. Regarding the phenolic content, significant differences were noticed among wines made from different grape varieties. Gallic acid and catechin were the dominant phenols in all analyzed samples. Also, wine made from Pinot Noir variety had the highest phenolic content in total. In conclusion, the developed procedure can be applied for fast and effective determination of phenols in wine without additional sample preparation and obtaining valuable information about these important compounds with potential health benefits.

Acknowledgement. This research was supported by the National Project of Technological Development - Ministry of Education, Science and Technological Development, Republic of Serbia (no. TP31020).

\section{References}

1. Xia, E. Q.; Deng, G. F.; Guo, Y. J.; Li, H. B. Int. J. Mol. Sci. 2010, 11, 622. 2. Saleem, T. S. M.; Basha, S. D. J. Cardiovasc. Dis. Res. 2010, 1, 171.

3. Fang, F.; Li, J. M.; Zhang, P.; Tang, K.; Wang, W.; Pan, Q. H.; Huang, W. D. Food Res. Int . 2008, 41, 53.

4. Pérez-Magariño, S.; González-San José, L. Food Chem. 2006, 96, 197. 5. Cvejić, J.; Atanacković, M. In: Processing and impact on active components in food ed. Preedy, V., Academic Press Elsevier, USA, 2015, p. 501.

6. Atanacković, M.; Petrović, A.; Jović, S.; Gojković-Bukarica, Lj.; Bursać, M.; Cvejić, J. Food Chem. 2012, 131, 513.

7. Fang, F.; Li, J. M.; Pan, Q. H.; Huang, W. D. Food Chem. 2007, 101, 428.

8. Gomez-Alonso, S.; Garcia-Romeroa, E.; Hermosin-Gutierrez, I. J. Food Compos. Anal. 2007, 20,618.

9. Vitrac, X.; Monti, J. P.; Vercauteren, J.; Deffieux, G.; Mérillon, J. M. Anal. Chim. Acta 2002, 458, 103.

10. Bravo, M. N.; Silva, S.; Coelho, A. V.; Vilas Boas, L.; Bronze, M. R. Anal. Chim. Acta 2006, 563, 84.
11. Dias, F. S.; Klassen, A.; Tavares, M. F. M.; David, J. M. Chromatographia 2013, 76, 559.

12. Arribas, A. S.; Martínez-Fernández, M.; Moreno, M.; Bermejo, E.; Zapardiel, A.; Chicharro, M. Electrophoresis 2014, 35, 1693.

13. Burin, V. M.; Grützmann Arcari, S.; Freitas Costa, L. L.; BordignonLuiz, M. T. J. Chromatogr. Sci. 2011, 49, 647.

14. González-Ruiz, V.; Olives, A. I.; Antonia Martín, M. Trends Anal. Chem. 2015, 64, 17.

15. Guiochona, G.; Gritti, F. J. Chromatogr. A 2011, 1218, 1915.

16. Hayes, R.; Ahmed, A.; Edge, T.; Zhang, H. J. Chromatogr. A 2014, $1357,36$.

17. Carrieri, C.; Milella, R. A.; Incampo, F.; Crupi, P.; Antonacci, D.; Semeraro, N.; Colucci, M. Food Chem. 2013, 140, 647.

18. Palacios, M. J.; Gordillo, B.; Gonzalez-Miret, M. L.; Hernanz, D.; Escudero-Gilete, M. L.; Heredia, F. J. J. Agric. Food Chem. 2014, 62, 6975.

19. Manns, D.; Mansfield, A. N. J. Chromatogr. A 2012, 1251, 111.

20. Silva Padilha, C. V.da; Miskinis, G. A.; Olinda de Souza, M. E. A.; Pereira, G. E.; , Oliveira, D.de; Bordignon-Luiz, M. T.; , Santos Lima, M.dos Food Chem. 2017, 228, 106.

21. Kim, M. Y.; Seguin, P.; Ahn, J. K.; Kim, J. J.; Chun, S. C.; Kim, E. H.; Seo, S. H.; Kang, E. Y.; Kim, S. L.; Park, Y. J.; Ro, H. M.; Chung, I. M. J. Agric. Food Chem. 2008, 56, 7265.

22. www.agilent.com, Accessed December 32017.

23. International Conference on Harmonisation of Technical Requirements for Registration of Pharmaceuticals for Human Use, ICH Harmonised Tripartite Guideline, Validation of Analytical Procedures: Text and Methodology Q2(R1), 2005, ICH: Geneva.

24. Snyder, L. R.; Kirkland, J. J.; Glajch, J. L. Practical HPLC method development, $2^{\text {nd }}$ ed., John Wiley \& Sons, New York, 1997, p. 13.

25. Cvetković, Ž. S.; Nikolić, V. D.; Savić, I. M.; Savić-Gajić, I. M.; Nikolić, Lj. B. Hem. Ind. 2015, 69, 679

26. López-Vélez, M.; Martínez-Martínez, F.; Del Valle-Ribes, C. Crit. Rev. Food Sci. Nutr. 2003, 43, 233.

27. Vinković Vrček, I.; Bojić, M.; Žuntar, I.; Mendaš, G.; Medić-Šarić, M. Food Chem. 2011, 124, 354.

28. Gürbüz, O.; Göcmen, D.; Dağdelen, F.; Gürsoy, M.; Aydin, S.; Şahin, I.; Büyükuysal, L.; Usta, M. Food Chem. 2007, 100, 518.

29. Sakkiadi, A. V.; Stavrakakis, M. N.; Haroutounian, S. A. LWT- Food Sci. Technol. 2001, 34, 410.

30. Soleas, G. J.; Dam, J.; Carey, M.; Goldberg, D. M. J. Agric. and Food Chem. 1997, 45, 3871.

31. Goldberg, D. M.; Karumanchiri, A.; Tsang, E.; . Soleas, G. J. Am. J. Enol. Vitic. 1998, 49, 23.

32. Cvejić, J. M.; Đekić, S. V.; Petrović, A. V.; Atanacković, M. T.; Jović, S. M.; Brčeski, I. D.; Gojković-Bukarica, Lj. C. J. Chromatogr. Sci. 2010, 48, 229.

33. Vlase, L.; Kiss, B.; Leucuta, S. E.; Gocan, S. J. Liq. Chromatogr. Relat. Technol. 2009, 32, 2105.

34. Minussi, R. C.; Rossi, M.; Bologna, L.; Cordi, L.; Rotilio, D.; Pastore, G. M.; Duran, N. Food Chem. 2003, 82, 409.

35. Ivanova-Petropulos, V.; Ricci, A.; Nedelkovski, D.; Dimovska, V.; Parpinello, G. P.; Versari, A. Food Chem. 2015, 171, 412. 